\title{
Endogenous Provision and Appropriation in the Commons ${ }^{1}$
}

\author{
by
}

Alain de Janvry, Nancy McCarthy, and Elisabeth Sadoulet

\section{Determinants of provision and appropriation}

When a resource is under common property, access is restricted to members of the community, creating the potential of avoiding the tragedy of the commons that characterizes resource use under open access (Bromley). Serious difficulties remain, however, in managing the resource in a way that is socially optimum because of the rival nature of appropriation by individual members. Achieving the social optimum requires either inducing a noncooperative behavior by individual members that mimics what cooperative behavior would dictate, or inducing cooperative behavior. A number of set ups have been identified where the first holds, for instance when the payoffs correspond to a chicken game, an assurance game, or tit-for-tat, or the Folk Theorem in repeated games (Bardhan, 1993; Nugent, 1993). There is a vast qualitative literature on the determinants of cooperation, with some success stories but also many failures (Wade, 1987; Ostrom, 1992). If, in addition, cooperation is costly, socially optimum resource use may deviate from the first best costless cooperative solution to an extent that reflects the importance of these costs (see section III below). Hence, even when there is cooperation, observed resource use relative to the costless social optimum appears as if there were different qualities of cooperation in communities characterized by differential costs of cooperating. If we are advocating cooperation as a solution to misuse of common property resources (CPR), we consequently need to develop models that can explain why we observe these presumed different qualities of cooperation across communities. While there are many "soft" arguments about the costs of cooperation, we lack a theory that formalizes the quality of cooperation achieved, expliciting the origins and consequences of transactions costs in determining cooperative outcomes. It is the first objectives of this paper to propose such a model.

For many CPR, use by a community member requires deciding not only on how much effort to make in appropriating the resource in a rival fashion, but also how much effort to deliver in providing the resource (Baland and Platteau). Provision decisions include participation to construction and maintenance of collective infrastructure (e.g., cleaning irrigation canals), protecting the CPR from encroachment by outsiders (surveillance), reforestation, and use of nets with larger mesh to allow protection of fry. Under non-cooperative behavior in a community with $M$ members, the provider chooses the level of effort, taking for given the level of provision of the other $M-1$ members. If the provider only appropriates $1 / M$-th of the outcome of his provision, effort at providing creates a positive externality on others, and each provider under-provides. This is the CPR equivalent to the Marshallian disincentive in sharecropping created by the fact that the tenant only captures a share of the product created by his labor provision. How much effort the non-cooperative provider will make hence depends on the rules for appropriation of the resource. These rules may be exogenous, for instance egalitarian sharing or sharing proportional to an asset position such as land to be irrigated. The total amount to be appropriated also depends on the quality of cooperation. In this case, the level of provision depends on the quality of cooperation achieved in appropriation.

1 Paper presented at the Allied Social Science Association meeting, Chicago, January 2-5, 1998. Alain de Janvry and Elisabeth Sadoulet are professors in the Department of Agricultural and Resource Economics, and members of the Giannini Foundation of Agricultural Economics, University of California at Berkeley. Nancy McCarthy is an economist at the International Livestock Research Institute, Nairobi, and the International Food Policy Research Institute, Washington D.C. 
If cooperation fails, and the good is a total stock to be allocated among members like water available in an irrigation system, increased appropriation by some implies lesser appropriation by others. This leads to eventual socially sub-optimal allocation, but without creating negative cost externalities across users. If, however, as in the case of grazing on CPR pastures, each community member only pays $1 / M$-th of the cost of what he appropriates, this creates a negative externality on others. This induces excess appropriation, replicating the tragedy of the commons within a closed CPR. Models of appropriation in CPR have usually conceptualized this effect taking the level of provision as given. This is for instance the case for the classical fisheries models developed by Dasgupta and Heal (1979) and Stevenson (1991) where the stock of fish is affected by appropriation, but not by a separate decision on provision. It is the second objective of this paper to propose a model that links provision to the quality of cooperation in appropriation when there are negative externalities in appropriation.

Finally, it is obvious that provision and the quality of cooperation in appropriation need to be simultaneously determined: provision depends on the quality of cooperation in appropriation; and the quality of cooperation in appropriation depends on the level of provision. The third objective of this paper is to show how this model can be constructed.

\section{Linking provision to cooperation}

We develop here a model where provision to a CPR depends on the level of cooperation in appropriation. An example is a situation where individuals can encroach on community land to carve agricultural plots which they cultivate individually, while raising livestock on the remaining CPR. Provision to the CPR consists in refraining from encroaching an excessive amount of land for agriculture. Incentive not to increase agriculture depends on the quality of livestock management on the CPR which, in turn, depends on the quality of cooperation in setting limits to the number of animals which each member can have. With better cooperation in managing CPR pastures, each individual would like to keep more land in pastures in order to raise a larger number of animals. This resets the boundary of community land use between agriculture and pastoralism in favor of the latter.

Define the following variables: Exogenous variables

$M \quad$ Number of members in the community $(i=1, \ldots, M)$

$H \quad$ Total community land ( $H$ for hectares)

$p_{a}, p_{l} \quad$ Prices of agriculture and livestock products, respectively

$f($.$) \quad Production function for agriculture with decreasing returns in land due to the presence of fixed$ factors

$z_{i}$ Fixed factors in agricultural production

$c_{i}$ Constant marginal cost associated with each animal

a Pasture productivity coefficient

$b \quad$ Pasture sensitivity to stocking coefficient.

Endogenous variables

$h_{i} \quad$ Size of individual agricultural plot carved from community land

$H_{c}=H-\sum_{i=1}^{M} h_{i} \quad$ Area left in common property pastures

$n_{i} \quad$ Number of animals grazed by individual $i$

$N \quad$ Total number of animals in the community.

$a-\frac{b N}{H_{c}}$ Weight gain function for one head of livestock (see Hart et al., 1989). 
Each household decides on $h_{i}$, given the stocking rate $N / H_{c}$ established by some quality of cooperative behavior on management of the common property pastures (to be established in section III). For each household, the problem is:

$$
\operatorname{Max}_{h_{i}} \Pi_{i}=p_{a} f\left(h_{i}, z_{i}\right)+p_{l} n\left(a-b \frac{N}{H_{c}}\right)-n c_{i},
$$

given the egalitarian appropriation rule $n=N / M$.

Let us express the actual stocking rate $N / H_{c}$ in deviation from the optimum stocking rate $\left(N / H_{c}\right)^{* *}$ that a central planner would have chosen as $N / H_{c}=\left(N / H_{c}\right)^{* *} \eta$, where $\eta \geq 1$ is thus defined as the level of overgrazing.

Solving the first order conditions for $f^{\prime}$ gives:

$$
f^{\prime}\left(h_{i} ; z_{i}\right)=\frac{b p_{l}}{p_{a}} \frac{1}{M}\left(\frac{N}{H_{c}}\right)^{* *} \eta\left[\left(\frac{N}{H_{c}}\right)^{* *}(2-\eta)+\frac{\bar{c}-c_{i}}{b p_{l}}\right] \text {. }
$$

Hence, there exists a negative externality in the allocation of pastures to the common pool: the optimum area in agriculture increases with $M$ as each individual only captures $1 / M$-th of the benefit from the marginal hectare he contributes to pastures by not encroaching further for agricultural production. Cooperation on the number of animals thus leads to an optimum stocking rate, but to an excessive allocation of land to food plots compared to a fully cooperative equilibrium since the decision to encroach remains non-cooperative. ${ }^{2}$ The expression also shows that individual provision of land to pastures increases when overgrazing $\eta$ decreases (i.e., the quality of cooperation increases).

The aggregate level of provision is thus:

$$
H_{c}=H-\sum_{i} h_{i}=f\left[+\left(\frac{N}{H_{c}}\right)^{* *},-\eta,-M,+p_{l},-p_{a}, c_{i}, z_{i}\right],
$$

where the degree of heterogeneity in the community is reflected by unequal cost efficiencies in raising livestock $\left(c_{i}\right)$ and household characteristics $\left(z_{i}\right)$. Communal land devoted to pastoralism thus increases with the optimum stocking rate $\left(N / H_{c}\right)^{* *}$ that reflects the quality of the pastures, with the quality of cooperation in appropriation (- $\left.\eta\right)$, and with the price of livestock. It decreases with the size of the community and with the price of agricultural products. This latter effect is due to the negative externality that prevails in provision, irrespective of the quality of cooperation in appropriation.

\section{Linking cooperation in appropriation to provision}

We now take as given the solution to the provision problem, resulting in a predetermined total amount of land in common pastures. The community should now decide on the optimum total number of animals to be grazed on these pastures so the group will maximize profits. The gains from cooperation in appropriation are well-known whenever there are negative externalities associated with use. The community, however, faces costs to cooperation -- costs involved in devising rules and in monitoring and enforcing any agreed upon stocking levels. Thus far in the literature, costs of cooperating have largely been considered "fixed", in the sense that they do not change with the

2 Under full cooperation, the optimum area in agriculture would be given by:

$$
f^{\prime}\left(h_{i} ; z_{i}\right)=\frac{b p_{l}}{p_{a}}\left(\frac{N}{H_{c}}\right)^{* *} \eta\left[\left(\frac{N}{H_{c}}\right)^{* *}(2-\eta)\right]
$$


agreed-upon level of use (see for example Seabright, 1993). Given fixed costs of cooperation, it would appear as if there are only two possible outcomes for the group: either costs are sufficiently high that no cooperation can be sustained, or costs are sufficiently low that cooperation can prevail But, if cooperation can be achieved, there is no reason for the group not to choose the best possible outcome. ${ }^{3}$ This is not what we observe when we carry observations across communities. To allow for varying levels of quality in cooperating, we introduce costs to cooperation which change with the level of agreed-upon stocking levels. ${ }^{4}$ This specification leads to the determination of an agreed-upon level of appropriation that is higher than the social optimum that would prevail if there were no costs of enforcement. This outcome resembles a variable "level" of cooperation, when it is in fact a fully cooperative outcome which balances benefits and costs of obtaining cooperation.

The literature is divided on the effect of the quality and abundance of the common resource, and hence on the effect of the level of provision, on the incentive to cooperate. One can argue that "cooperation" is more likely to arise as the resource becomes more scarce (as availability declines, at some point, the community gets together and decides in a Hirschman-type response that it has to organize for a more efficient use (Hirschman, 1984)), or that cooperation is more likely to obtain when the resource is sufficiently abundant to generate high gains from cooperating (Bardhan, 1993). In the framework that we develop here, as the level of provision influences both the benefits of cooperation and the costs of obtaining this cooperation, the optimal level of appropriation that the group will cooperatively choose depends on the level of provision of the common resource.

Consider a two-person game over the number of animals $\left(n_{i}, n_{j}\right)$ to graze on a common property pasture of given size $H_{c}$. The profit from grazing is defined as above:

$$
\pi_{i}\left(n_{i}, n_{j}\right)=p_{l} n_{i}\left[a-\frac{b\left(n_{i}+n_{j}\right)}{H_{c}}\right]-c n_{i} \quad i, j=1,2 \quad i \neq j .
$$

Each of the two players has two strategies: one is to cooperate and graze the number of animals agreed upon in a joint maximization, $n_{i}=n^{*}$, and the other to not cooperate and graze the number of animals consistent with individual maximization given the number of animals grazed by the other player, $n_{i}^{\circ}\left(n_{j}\right)$. Let us call $n_{i}^{\circ \circ}$ the Nash non-cooperative solution when neither player cooperates.

We hypothesize that the enforcement costs will be a function of (1) private incentives for members to deviate from any agreed upon level, and (2) socio-cultural characteristics that either help or hinder a group's ability to devise and maintain an institution for "governing the commons". First, we develop the concept of incentives to deviate and then discuss their relationship with the costs of attaining a cooperative solution. Secondly, we consider the socio-cultural characteristics which will act as shift variables in the cost function.

As explicitly captured in Prisoner's Dilemma games, there are two types of incentives for a person not to cooperate. If he believes that all others will cooperate, then his best response is to not cooperate, and to add more animals. This is the incentive to cheat which is equal to the difference between the profit obtained by abiding to the agreement (given that the other person cooperates) and the profit of optimally cheating:

$$
I_{i}^{C h}=\pi_{i}\left(n_{i}^{\circ}\left(n^{*}\right), n^{*}\right)-\pi_{i}\left(n^{*}, n^{*}\right) .
$$

3 This statement requires that we abstract from imperfect information problems. In our model, we assume perfect information on use rates, which seems to be particularly well-suited in describing pastoral operations in village economies.

${ }^{4}$ A few researchers have been concerned with the optimal number of group members, and specify that transactions costs involved in supporting cooperative agreements are likely to increase with the number of members. In our model, as in village economies in general, the membership base is fixed. 
The second type of incentive to consider is associated with avoiding losses that would be sustained if one were to be duped, e.g. of cooperating while the other person cheats. The incentive to not be duped is the potential gain in profit from cheating given that individual $j$ himself cheats (i.e., plays its best response to whatever $i$ decides to do, which is $n_{j}^{\circ}\left(n^{*}\right)$ if $i$ cooperates and $n^{\circ \circ}$ if $i$ does not cooperate):

$$
I_{i}^{N D}=\pi_{i}\left(n^{\circ \circ}, n^{\circ \circ}\right)-\pi_{i}\left(n^{*}, n_{j}^{\circ}\left(n^{*}\right)\right) .
$$

We assume that the equilibrium cooperation level can be enforced if the group undertakes supervision and punishment measures that are costly. This enforcement cost increases with the incentives to defect as follows:

$$
\gamma^{C h} \sum_{i} I_{i}^{C h}+\gamma^{N D} \sum_{i} I_{i}^{N D} \text {, where } \gamma^{C h} \text { and } \gamma^{N D} \text { are unit enforcement costs. }
$$

Many researchers have enumerated factors associated with successful management of the commons (c.f. Ostrom, 1990; Oakerson, 1992; Baland \& Platteau, 1996). These factors include socio-cultural characteristics which decrease the costs of monitoring and enforcement, such as proximity, ethnic homogeneity, power of social sanctions, and ability of traditional authorities to regulate use. They also include physical characteristics such as resource quantity and quality which are affected by the level of aggregate provision. Hence, $\gamma^{C h}$ and $\gamma^{N D}$ will be function of these features and of provision.

We assume that the objective of the group is to maximize the net welfare gain from cooperation:

$$
W=\sum_{i} \pi_{i}\left(n^{*}, n^{*}\right)-\gamma^{C h} \sum_{i} I_{i}^{C h}-\gamma^{N D} \sum_{i} I_{i}^{N D}-\sum_{i} \pi_{i}\left(n^{\circ \circ}, n^{\circ \circ}\right) .
$$

This cooperative solution is only meaningful if $W^{*}>0$. It will be enforceable without explicit transfer if there is a positive profit gain, $\pi_{i}\left(n^{*}, n^{*}\right) \geq \pi_{i}\left(n^{\circ \circ}, n^{\circ \circ}\right)$, for each producer $i$. The constrained cooperative solution is (see McCarthy, Sadoulet, and de Janvry, 1997):

$$
\frac{n^{*}}{H_{c}}=\frac{a-\bar{c} / p_{1}}{4 b}\left(\frac{1+\frac{3}{2} \gamma^{C h}+\frac{1}{2} \gamma^{N D}}{1+\frac{9}{8} \gamma^{C h}+\frac{1}{4} \gamma^{N D}}\right)=\frac{a-\bar{c} / p_{1}}{4 b} \eta \quad \text { if } \gamma^{N D} \leq 2,
$$

where $\eta$ is overgrazing, defined as the economically optimal stocking rate under costly cooperation relative to the optimal level that would be obtained if cooperation had no cost. For $\gamma^{N D}>2$, the only enforceable stocking rate is the non-cooperative level, $\frac{n^{*}}{H_{c}}=\frac{n^{\circ 0}}{H_{c}}=\frac{a-\bar{c} l p_{l}}{3 b}$.

This expression shows that the enforceable aggregate stocking rate lies between the costless cooperative equilibrium $N^{* *}$ (as calculated in standard cooperative models) and the non-cooperative equilibrium $N^{\circ}$ :

$$
\frac{N^{* *}}{H_{c}}=\frac{a-\bar{c} / p_{l}}{2 b}<\frac{N^{*}}{H_{c}}<\frac{N^{\circ}}{H_{c}}=2 \frac{a-\bar{c} / p_{l}}{3 b} \quad \text { for } \gamma^{C h} \geq 0 \quad \text { and } \quad 0 \leq \gamma^{N D} \leq 2 \text {. }
$$

These results show that overgrazing increases with the unit costs of enforcement, and that it tends to the non-cooperative level for very high unit enforcement costs, $\gamma^{C h} \rightarrow \infty$ or $\gamma^{N D} \geq 2$. Hence, all socioeconomic community member characteristics $\left(z_{i}\right)$ and physical characteristics of the resource $\left(z_{H}\right)$ that contribute to the reduction of the supervision and enforcement costs will support cooperation at a higher level of efficiency in resource use. If, as expected, surveillance and enforcement are more expensive on larger expanses of pastures, then 
the aggregate stocking rate will be a decreasing function of resource provision, $H_{c}$. Some have argued, however, that cooperation may increase with resource provision since it increases the returns from cooperating (Bardhan, 1993). Hence, there is an ambiguous sign between $H_{c}$ and the costs of cooperation. Following Olson (1965), these costs should, however, unambiguously increase with $M$, the size of the community.

The aggregate stocking rate $N^{*} / H_{c}$ is an increasing function of $\left(a-\bar{c} / p_{l}\right) / b$. Hence, the optimal stocking rate under costly cooperation is higher on better pastures (higher $a$ and lower $b$ ) and for more efficient livestock production (lower $\bar{c}$ ). We can also show that (1) profits under both non-cooperation and cooperation, (2) individual profit gains from cooperation, (3) incentives to defect, and (4) the overall welfare gain from cooperation are all increasing with $\frac{\left(a-\bar{c} / p_{l}\right)^{2}}{b} p_{l} H_{c}$. Profits under cooperation are a decreasing function of the enforcement costs $\gamma^{C h}$ and $\gamma^{N D}$. This shows that gains from cooperation are larger on better pastures and for more efficient livestock production, and in communities with lower enforcement costs.

We can summarize the comparative static results as follows:

$\frac{N^{* *}}{H_{c}}=f\left(+a,-b,-\bar{c} / p_{l}\right)$

$\frac{N^{*}}{H_{c}}=\frac{N^{* *}}{H_{c}} \eta\left(+\gamma^{C h},+\gamma^{N D}\right)$

$\pi=\pi\left(+\frac{N^{* *}}{H_{c}},+H_{c},+a,-\bar{c} / p_{l},-\gamma^{C h},-\gamma^{N D}\right)$,

$W=W\left(+\frac{N^{* *}}{H_{c}},+H_{c},+a,-\bar{c} / p_{l},-\gamma^{C h},-\gamma^{N D}\right)$

$\gamma^{k}=\gamma^{k}\left( \pm H_{c},+M, z_{i}, z_{H}\right) \quad$ for $k=C h, N D$.

(2)

The literature has seldom addressed the potential role of resource abundance, here affected by the level of provision, in shaping the conditions for cooperation. Bardhan (1993) has proposed that cooperation is less likely when resources are either very scarce or very abundant, creating the equivalent of a "Laffer curve" between resource abundance (provision) and cooperation: when resources are scarce, the benefit from default is very high and cooperation breaks down; when resources are abundant, the opportunity cost of waste and inefficiency does not seem so crucial, and cooperation may not be worth the cost. The link between resource abundance (provision) and incentive to cooperate is taken into account in our formulation. However, because all profits and incentives are proportional to the level of resource endowment, the level of overgrazing $\eta$ is not influenced directly by this effect on incentive, and the resource endowment only influences the quality of cooperation through its effect on the costs $\gamma$

\section{Joint determination of provision and appropriation}

In section II, we have shown that the decision on provision is influenced by the expected quality of cooperation, as reflected by the chosen stocking rate. In section III, we established that when cooperation is costly to enforce, a community will decide to set a stocking rate closer to the individual optimum in order to reduce the incentives to defect. This intermediate quality of cooperation, as compared to what would be obtained if supervision and enforcement were costless, is itself function of provision to the CPR. Taken together, these two relationships determine endogenous levels of provision and appropriation. This can be summarized with the two functions derived from (1) and (2) above: 


$$
\begin{array}{ll}
H_{c}=f\left[+\left(\frac{N}{H_{c}}\right)^{* *},-\eta,-M, z_{i}\right] & \text { from the provision decision, } \\
\eta=\eta\left( \pm H_{c},+M, z_{i}, z_{H}\right) & \text { from the appropriation decision. }
\end{array}
$$

Comparative statics results indicate that:

- When enforcement costs decrease with resource abundance, increasing group size unambiguously induces less provision and more appropriation of the CPR (see Figure 1a). Hence, the general equilibrium effects of increasing group size (i.e., when provision and appropriation are jointly determined) reinforce the partial equilibrium effects (i.e., when provision is for a given appropriation rule, and when appropriation is for given provision).

- When the cost of enforcing cooperation increases with resource abundance, the general equilibrium effects of increasing group size aggravate underprovision of the resource. However, this reduction in provision, by reducing resource abundance, mitigates the direct negative effect of group size on the quality of cooperation, making the result indeterminate as opposed to partial equilibrium results. Hence, contrary to partial equilibrium results, it is not always the case that a larger group size results in more overgrazing (see Figure 1b).

- Better quality of resources (as reflected by a higher level of $\left(N / H_{c}\right)^{* *}$ ) induces a higher level of provision, and a higher (lower) quality of cooperation if the costs of enforcing cooperation decrease (increase) with abundance.

- The role of heterogeneity is not properly captured in this formulation. It comes implicitly through the individual characteristics, $z_{i}$. If, as one would expect, heterogeneity has a negative effect directly on the costs of enforcing cooperation in appropriation, but no direct effect on aggregate provision, then the negative effect on cooperation in appropriation does induce a negative spillover effect on provision.

\section{Conclusion}

We have developed a model explaining jointly the incentives to provide to and to appropriate from a common property resource. In that model, provision is non-cooperative while appropriation can be cooperative, but the quality of cooperation in appropriation is endogenous in response to the costs of deterring incentives to defect. We have solved this problem as though there were two separate decision-makers, reacting to each others' decisions: individual community members provide in response to the quality of cooperation in appropriation; and cooperation in appropriation is determined in response to aggregate provision. This has led us to identifying the role of exogenous variables such as community size, quality of natural resources, and heterogeneity of membership on the joint equilibrium between provision and appropriation. We saw that the resulting levels of provision and appropriation differ from those predicted from separate decisions.

If the agency that decides on cooperation in appropriation anticipates the impact that appropriation has on provision, the problem becomes a principal agent situation. The community thus has only one instrument -cooperation in appropriation -- to resolve two problems: achieve a high quality level of cooperation to reduce overappropriation and to induce a higher level of provision. Since appropriation responds positively to the quality of cooperation, the incentive for the community is to increase spending in enforcing cooperation in appropriation since it creates a positive externality on provision. Hence, we should observe higher quality cooperation in communities where provision by members is more sensitive to appropriation. Incentives to cooperate should thus be greater in forestry and grazing where provision is important than in fisheries where there is no provision problem. 
Finally, cooperation may well apply to both provision and appropriation decisions. In this case, the community can internalize all externalities and achieve a true social optimum. This model of costly cooperation with joint provision and appropriation decisions is left to be developed.

Figure 1. Changes in provision and appropriation as group size increases

$$
\gamma=\text { enforcement costs, } H_{c}=\mathrm{CPR} \text { abundance }
$$

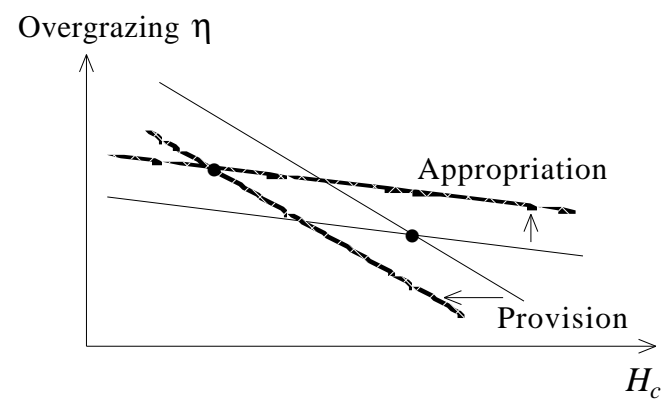

a. $\gamma$ decreasing in $H_{c}$

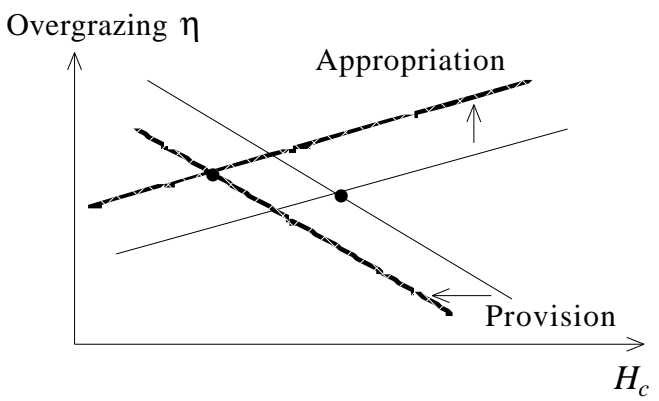

b. $\gamma$ increasing in $H_{c}$

\section{References}

Baland, Jean-Marie and Jean-Philippe Platteau. 1996. Halting Degradation of Natural Resources: Is There a Role for Rural Communities? Cambridge University Press.

Bardhan, Pranab. 1993. "Analytics of the Institutions of Informal Cooperation in Rural Development". World Development, 21(4): 633-40.

Bromley, Daniel. Making the Commons Work: Theory, Practice, and Policy. San Francisco: Institute for Contemporary Studies Press, 1992.

Dasgupta P. and G. Heal. Economic Theory of Exhaustible Resources. Cambridge: Cambridge University Press, 1979.

Hart, R.H., Marilyn Samuel, Peter Test, and Michael Smith. 1989. "Cattle, Vegetation, and Economic Responses to Grazing System and Grazing Pressure”. Journal of Range Management, 41 (4): 282-287.

Hirschman, A. O., Getting Ahead Collectively: Grassroot Experiences in Latin America, New York: Pergamon Press, 1984.

McCarthy, Nancy, Elisabeth Sadoulet, and Alain de Janvry. 1997. "Common Property Resource Appropriation Under Costly Cooperation". Working Paper. Department of Agricultural and Resource Economics, University of California at Berkeley.

Nugent, Jeffrey. 1993. "Between State, Markets, and Households: A Neo-institutional Analysis of Local Organizations and Institutions. World Development, 21(4): 623-32.

Oakerson, Ronald. "A Model for the Analysis of Common Property Problems", in Proceedings of the Conference on Common Property Resource Management, National Research Council, pp. 13-30. Washington D.C.: National Academy Press, 1986.

Olson, Mancur. The Logic of Collective Action: Public Goods and the Theory of Groups. Cambridge, MA: Harvard University Press, 1965

Ostrom, Elinor. 1992. Crafting Institutions for Self-Governing Irrigation Systems. San Francisco: Institute for Contemporary Studies Press. 
Seabright, Paul. "Managing the Local Commons: Theoretical Issues in Incentive Design", Journal of Economic Perspectives, Vol. 7, No. 4, Fall 1993, pp. 113-34.

Stevenson, Glenn. 1991. Common Property Economics: A General Theory and Land Use Applications. Cambridge University Press.

Wade, Robert. Village Republics: Economic Conditions for Collective Action in South India. Cambridge: Cambridge University Press, 1987. 